\title{
CONSTRUCTING THE PARAMETRIC FAILURE FUNCTION OF THE TEMPERATURE CONTROL SYSTEM OF INDUCTION CRUCIBLE FURNACES
}

\author{
Dmitriy Demin \\ Department of Foundry Production \\ National Technical University «Kharkiv Polytechnic Institute» \\ 2 Kyrpychova str., Kharkiv, Ukraine, 61002 \\ litvol1@kpi.kharkov.ua
}

\begin{abstract}
The objects of the study were diagnostic features that allow determining the quality of controlling temperature modes of induction crucible melting. For this, in the normalized space of feature factors, which are the content of $\mathrm{SiO}_{2}$ and $\mathrm{FeO}+\mathrm{Fe}_{2} \mathrm{O}_{3}$ in slag, a discriminant function is constructed and a decision rule is obtained in the form of a linear classifier, which allows determining in which mode the process was carried out. It is shown that this rule is the basis for identifying an event qualified as a parametric failure, and it can be included in the general structure of the parametric failure function.

The parametric failure function constructed for the temperature control system of induction crucible melting makes it possible to ascertain that the control system does not meet the specified requirements for a specific temperature mode of melting. The mechanism of inferencing regarding the occurrence of a parametric failure based on this function is as follows. If the decision rule showed that the object belongs to the «low-temperature mode» class, although the process under these conditions should have been carried out in the high-temperature mode, a parametric failure is recorded. In this case, the numerical value of this function takes the value of «1», otherwise - «0». The inferencing mechanism works similarly if, on the basis of the decision rule, it is revealed that the process was carried out in the high-temperature mode, although under these conditions it should have been carried out in the low-temperature mode.

Based on the constructed parametric failure function, practical problems related to planning maintenance of the temperature control system integrated into the melting complex or organizational and technical measures aimed at minimizing violations of the melting regulations can be solved.
\end{abstract}

Keywords: parametric failure function, temperature control, induction crucible furnace, discriminant function, classification rule.

DOI: $10.21303 / 2461-4262.2020 .001489$

\section{Introduction}

Modern views on the issue of optimal regulation of thermal modes for melting ferrous alloys in induction melting furnaces are based on the need to follow the «all-inclusive» paradigm. It involves deep integration of electrical and automated solutions for the creation of melting systems, including using intelligent melting control elements. This is illustrated by the ready-made solutions offered on the market of induction furnaces. Such solutions can be found, for example, in [1-3]. Such integrated solutions imply the need for scientific research in terms of both improvement of power electronics $[4,5]$, and process control based on the study of physical processes occurring in furnaces, depending on electrical modes of melting [6, 7]. The importance of combining these two approaches, one representing the electric power aspect, and the other - the physicochemical aspect, is evident in solving the existing problems related to the quality control of the melting process. This circumstance is noted in [8], where, to solve the problem of choosing the optimal melting strategy, an attempt was made to use the ideas of the statistical game theory and the synthesis of an optimal temperature controller based on a multi-alternative description of the final state [9]. In this case, the final state is described by a family of suboptimal solutions in a parametric form by means of ridge analysis of a mathematical model of the «composition - property» type [10,11], which are built on the basis of regression analysis, including the use of artificial orthogonalization methods [12].

Since the final composition of the alloy is formed by complex physicochemical processes that occur both in the liquid phase in parallel and sequential stages, and in solid phases until complete crystallization, the determining factor to be controlled is temperature. It is the temperature mode of melting that should provide such temperature values at which the required direction and speed of the physicochemical processes occurring in the furnace crucible as an open system are 
guaranteed. The effect of temperature on the course of these processes is manifested in the known dependence of the reaction rate constants on temperature, obeying the Arrhenius equation:

$$
k=A \exp \left(-\frac{E_{A}}{R T}\right),
$$

where $A$ is the preexponential factor, $E_{A}$ is the process activation energy, $R$ is the universal gas constant, $T$ is the temperature.

In the production of complex alloys, for example, alloyed and modified with a set of elements that have an opposite effect on structure formation, it is necessary to take into account the multifactorial effect of melting parameters on the final composition of the alloy. The mechanisms of this influence are related to changes in the parameters of the Arrhenius equation [13], so a targeted control effect should be selected based on an understanding of how the temperature trajectory will affect the course of physicochemical processes for alloys of different chemical compositions. Deviations from optimal trajectories can cause the composition of the alloy at the end of the process to differ from the specified one, regulated by technical requirements. Considering the probability that the content of each element of the chemical composition falls within a given range as the quality criterion of the melting process, the concept of parametric reliability of the melting temperature control system can be used. Namely, the temperature control system can be considered parametrically reliable if it provides a temperature trajectory at which the rate constants $k$ of physicochemical processes ensure that the content of each element of the chemical composition at the end of the process falls into the range regulated by the requirements. Obviously, it is hardly possible to solve this problem in full, due to the complexity and multifactorial nature of the processes taking place in the crucible of an induction furnace, but a solution can be obtained with regard to priority parameters. Such parameters can be, for example, elements of the chemical composition that most significantly affect a particular quality criterion of the alloy, in accordance with the mathematical model «composition - property». And since the final product of the physicochemical process in induction melting includes not only the alloy but also slag, which plays an important role in controlling the reduction processes of melting, it makes sense to assume that the composition of the slag may indirectly indicate the temperature mode at which melting was carried out. It should be noted that the temperature mode does not mean a deterministic temperature value, but a temperature range, which provides a given course of the process, the final result of which is the production of an alloy of given chemical composition. This is the problem that the temperature control system should solve. With this consideration, the parametric failure of the control system should be understood not as an event that the temperature values fall outside the tolerance range, but an event that the temperature mode does not correspond to that specified by the melting regulations. Accordingly, the parametric reliability of the temperature control system should be understood as its ability to provide a given technological regulation of melting. In conditions where continuous monitoring of the state of the control system is impossible, indirect methods of assessment are required. That is why, the assumption was tested in this work that the slag parameters can be indirect diagnostic indicators for assessing the quality of controlling the temperature mode of melting, on the basis of which it becomes possible to judge the parametric reliability of the control system.

\section{Materials and methods}

\section{1. Working hypothesis}

It is assumed that the composition of the slag obtained during melting structural cast iron in an induction crucible furnace indicates whether the process was carried out under a low-temperature or high-temperature mode. Traditionally, the first is characterized by the temperature range $T=1.250 \pm 50{ }^{\circ} \mathrm{C}$, and the second - by the temperature range $T=1.450 \pm 50{ }^{\circ} \mathrm{C}$. If it turns out that the actual composition of the slag indicates that the process was conducted in a low-temperature mode, although it should have been carried out in a high-temperature mode under these conditions, a parametric failure is recorded. If monitoring is carried out at different time intervals, then a flow of events qualified as parametric failures can be formed, on the basis of which it is possible to simulate the system operation, making adjustments to the operation process. So, if the furnace complex does not contain automation elements, and the process is carried out manually, then the presence 
of such a failure may indicate a violation of the melting regulations. If the furnace complex is automated and contains an integrated temperature control circuit, such a failure indicates the presence of faulty elements in the circuit and requires maintenance. The same applies to the case when the results of the slag analysis revealed that the process was carried out in a high-temperature mode, although it should have been carried out in a low-temperature mode under these conditions.

\section{2. Experimental data}

To obtain theoretical results confirming or refuting the hypothesis, experimental and industrial data were selected [14]. A fragment of such experimental and industrial data, which are the basis of theoretical verification, is given in Table $\mathbf{1}$.

Table 1

Experimental and industrial data

\begin{tabular}{|c|c|c|c|c|c|}
\hline \multirow{2}{*}{$\begin{array}{l}\text { Sampling time since the beginning of slag } \\
\text { formation, min }\end{array}$} & \multicolumn{5}{|c|}{ Slag composition, $\%$} \\
\hline & $\mathrm{SiO}_{2}$ & $\mathrm{CaO}$ & $\mathrm{FeO}+\mathrm{Fe}_{2} \mathrm{O}_{3}$ & MnO & $\mathrm{Al}_{2} \mathrm{O}_{3}$ \\
\hline \multicolumn{6}{|c|}{ Low-temperature mode } \\
\hline 0 & 39.32 & 2.08 & 40.77 & 1.31 & 11.22 \\
\hline 10 & 44.55 & 2.13 & 35.92 & 2.27 & 14.11 \\
\hline 20 & 47.16 & 2.52 & 31.18 & 1.2 & 13.18 \\
\hline 30 & 50.17 & 2.76 & 29.4 & 0.75 & 14.14 \\
\hline 40 & 53.22 & 3.18 & 23.55 & 1.15 & 13.9 \\
\hline 50 & 54.91 & 3.16 & 23.11 & 1.02 & 11.20 \\
\hline \multicolumn{6}{|c|}{ High-temperature mode } \\
\hline 0 & 56.62 & 3.11 & 20.78 & 1.19 & 12.15 \\
\hline 10 & 65.38 & 3.14 & 16.82 & 0.93 & 7.55 \\
\hline 20 & 76.18 & 3.18 & 7.14 & 2.48 & 7.42 \\
\hline 30 & 70.85 & 4.11 & 10.12 & 1.22 & 10.55 \\
\hline 40 & 69.95 & 3.59 & 9.86 & 0.41 & 12.44 \\
\hline
\end{tabular}

Note: the sampling time since the beginning of slag formation for each mode corresponds to the number of the experimental point $0 \rightarrow$ No. 1, 10 $\rightarrow$ No. 2, 20 $\rightarrow$ No. 3, 30 $\rightarrow$ No. 4, 40 $\rightarrow$ No. 5, 50 $\rightarrow$ No. 6 .

\section{3. Research methods}

For the study, pattern recognition methods were selected. The rationale for this choice was dictated by the following. If we consider two options for the modes of the melting process (Table 1), each of them forms its own cluster, described by a set of data - feature factors, the content of slag components. The temperature control system should provide the selected temperature range in accordance with the melting task, the result of which should be the specified chemical composition of the alloy. Under specific process conditions in acid-lined furnaces at the rates of charge consumption, ensuring a given chemical composition, slag with the composition that depends on all these conditions is formed. Thus, the task is to obtain a decision rule that allows, in the space of factors - the content of the most essential slag components - referring the process to one of the clusters, either low-temperature or high-temperature. In other words, it is necessary to implement an algorithm that allows obtaining a classification rule that will attribute an object to one of the clusters with a high degree of reliability. As noted in [15], most of the pattern recognition algorithms are representatives of parametric families. Even in the case of linearly inseparable samples, it is possible to construct a continuum of hyperplanes that correctly classifies all sampling objects. Parametric classification makes it possible, with sufficient accuracy, to classify objects as «good - defective» [16-18], or the process stages responsible for the formation of defects $[19,20]$, in the field of metallurgical technologies. Restrictions imposed on these methods related to the requirement of equality of covariance matrices and conformity of the distribution law of the feature factor values to the normal one can be taken into account or partially removed using special combined methods [21-23]. The results of [16-23] suggest that for the considered problem of classifying states «low-temperature mode» - «high-temperature mode» in the 
space of feature factors of the content of slag components, it is advisable to use parametric methods of classification. However, it should be borne in mind that there remains uncertainty in the selection of significant factors, and the sample size can be potentially small for a qualitative assessment of sample functions. In addition, an increase in the number of such factors will inevitably lead to an increase in the size of the covariance matrices to be inverted. Under these conditions, with an arbitrary distribution of experimental points in the feature factor space, it is difficult to expect the fulfillment of the above conditions, which constitute the essence of the restrictions on parametric classification methods. Therefore, the choice of feature factors was made on the basis of practical experience, based on the fact that the main components of the slag, which make it possible to judge the physical and chemical processes in the «melt - slag - furnace atmosphere» system when using an acidic lining, are silicon dioxide and iron oxides. So, in the given initial data, $\mathrm{SiO}_{2}\left(x_{1}\right)$ was chosen as the first factor and $\mathrm{FeO}+\mathrm{Fe}_{2} \mathrm{O}_{3}\left(x_{2}\right)$ - as the second. They make it possible to judge the final state of the controlled melting process in acid-lined induction crucible furnaces, since the values of these factors depend on the temperature trajectory provided by the temperature control system.

Fig. 1 presents the process diagram showing the relationship of the control parameters with the mechanisms of forming the final state, if it is estimated in the $« \mathrm{SiO}_{2}-\mathrm{FeO}+\mathrm{Fe}_{2} \mathrm{O}_{3} »\left(x_{1}-x_{2}\right)$ coordinates, and Fig. 2 - the circuit diagram of the furnace [24] with the given control loops for the electrical and thermal modes of the process.

Fig. 1 shows that when choosing the low-temperature melting mode, iron is reduced from $\mathrm{FeO}$ in two parallel reactions: melt silicon and melt carbon, which leads to saturation of the slag with $\mathrm{SiO}_{2}$. In this case, the $\mathrm{FeO}$ content in the slag decreases, which is compensated continuously during melting by the addition of new portions of the charge. This causes the content of iron oxides in the slag to remain high in the low-temperature mode of the process (Table 1).

Under the high-temperature mode, the reaction of reduction of iron oxides by melt carbon is more active, while the reduction of silica proceeds much more slowly. This results in the slag rapidly becoming highly siliceous, as can be seen from Table 1 by the content of $\mathrm{SiO}_{2}$ in the slag.

From the analysis of the ongoing processes, it can be concluded that two classes of objects can be distinguished - class A (low-temperature mode) and class B (high-temperature mode) - in the space of selected feature factors, each of which forms its own cluster, grouped around its center of gravity. This center of gravity corresponds to the mathematical expectation of its class, on the basis of which it is possible to carry out the procedure of parametric classification according to the known formulas $[25,26]$, systematically presented in the form of an algorithm shown in Fig. 3.

Fig. 3 presents the following notation:

$\mathbf{X}$ - matrix of values of feature factors ( $\mathbf{X}_{\mathbf{A}}$ and $\mathbf{X}_{\mathbf{B}}$ - for classes A and B, respectively),

$x_{k \max }-$ maximum value of the $k$-th feature factor,

$x_{k \min }-$ minimum value of the $k$-th feature factor,

$x_{k j}^{n o r m}$ - normalized value of the $k$-th feature factor in the $j$-th implementation,

$N_{i}$ - number of experiments in the $i$-th class (cluster),

$\mathbf{m}_{\mathrm{A}}, \mathbf{m}_{\mathrm{B}}-$ mathematical expectation of classes A and B, respectively,

C- covariance matrix,

$f(\mathbf{X})$ - discriminant function,

$P(A), P(B)$ - probabilities of classes A and $\mathrm{B}$, respectively,

$f_{0}$ - threshold value of the discriminant function,

$p_{i}-$ probability of correct classification of objects,

$n_{i}^{+}$- number of correctly classified objects,

W - linear transformation matrix,

$\overline{D^{2}}$ - intraclass distance for the class,

$\sigma_{k}^{2}$ - unbiased variance of the class,

$\underline{N}$-dimension of the feature factor space,

$\overline{a_{k}^{j}}$ - mean coordinate value of the image vector describing the position of the object in the feature factor space,

$\overline{D^{2}}$ - intraclass distance in the coordinate system obtained by the linear transformation of the original feature factor space. 


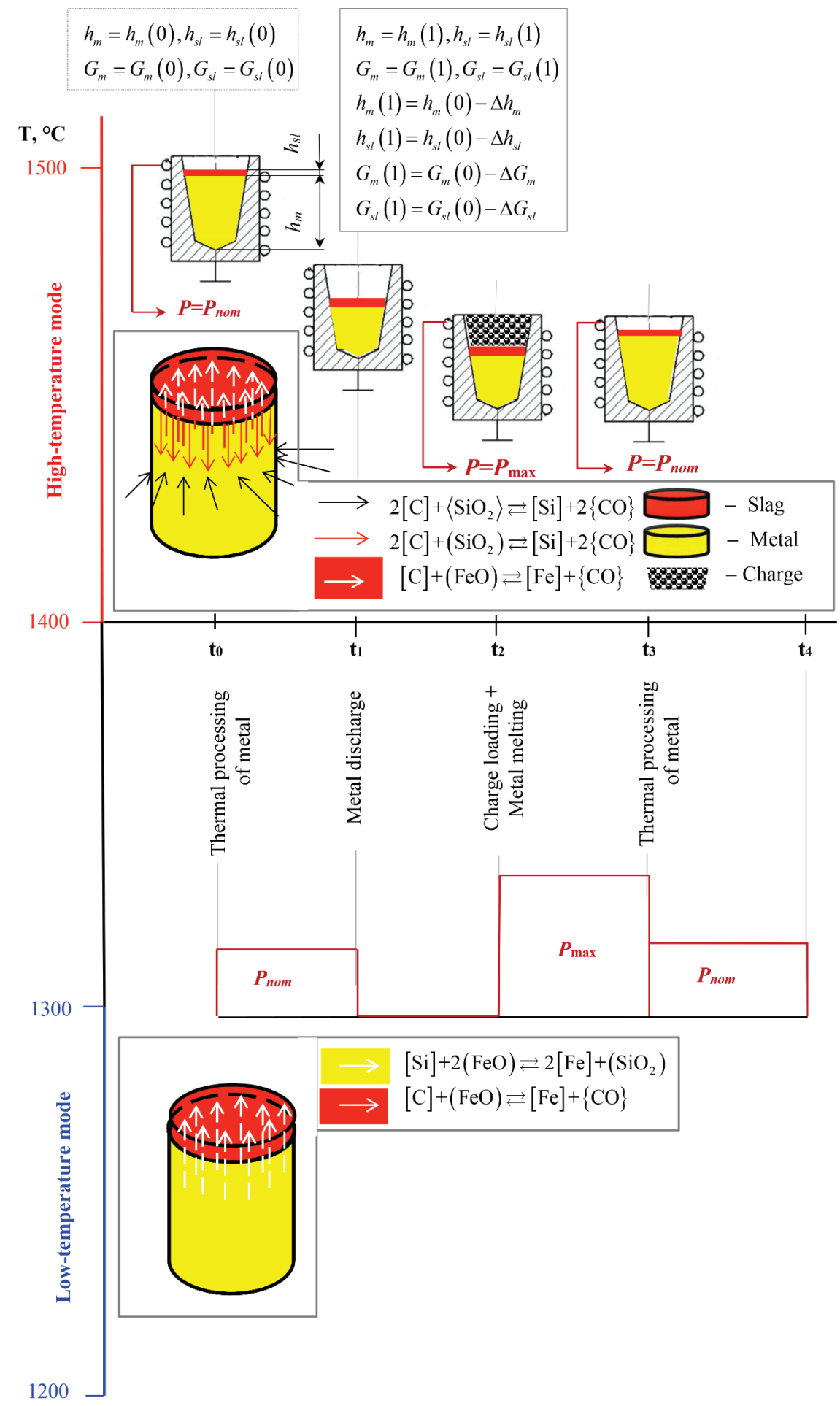

Fig. 1. Process diagram showing the relationship of control parameters with the mechanisms for forming the final state: $P$ - input power $\left(P_{n o m}\right.$ - nominal power, $P_{\max }-$ maximum power); $h_{m}=h_{m}\left(t_{i}\right)$ - melt depth in the crucible; $h_{s l}=h_{s l}\left(t_{i}\right)$ - slag layer thickness; $G_{m}=G_{m}\left(t_{i}\right)$ - melt mass; $G_{s l}=G_{s l}\left(t_{i}\right)$ - slag mass; $t_{i}$ - time points of the melting process; $\Delta h_{m}, \Delta h_{s l}, \Delta G_{m}, \Delta G_{s l}-$ decrease in melt depth, slag layer thickness, melt mass, slag mass, respectively, after the next melt portion

is delivered from the furnace; $[\mathrm{C}],[\mathrm{Si}],[\mathrm{Fe}]$ - content of carbon, silicon, iron in the melt; $\left(\mathrm{SiO}_{2}\right),(\mathrm{FeO})$ - content of silicon and iron oxides in the slag; $\{\mathrm{CO}\}$ - content of carbon monoxide in the gas phase; $\left\langle\mathrm{SiO}_{2}\right\rangle$ - content of silicon dioxide in the slag 


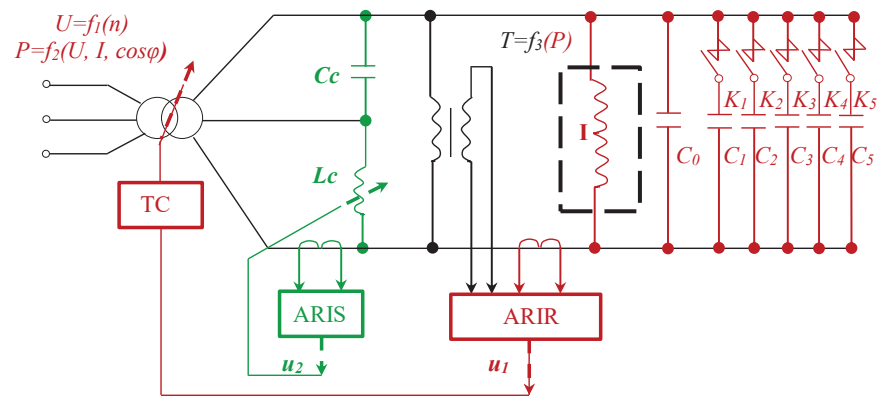

Fig. 2. Circuit diagram of the furnace demonstrating the principle of controlling electric (green marking) and thermal (burgundy marking) modes: TC - tap changer, $B_{C}$ - balancing capacity, $L_{C}$ - balun reactor, I - furnace inductor, $C_{i}$ - capacitance of the balancing capacitor battery, $K_{1}-K_{5}-$ battery capacity control contactors, ARIS - balun controller, ARIR - automatic power controller, $u_{1}$ - power control, $u_{2}$ - electric mode control, $I$ - current, $U$ - voltage, $n$ - transformer voltage tap number, $T$ - temperature

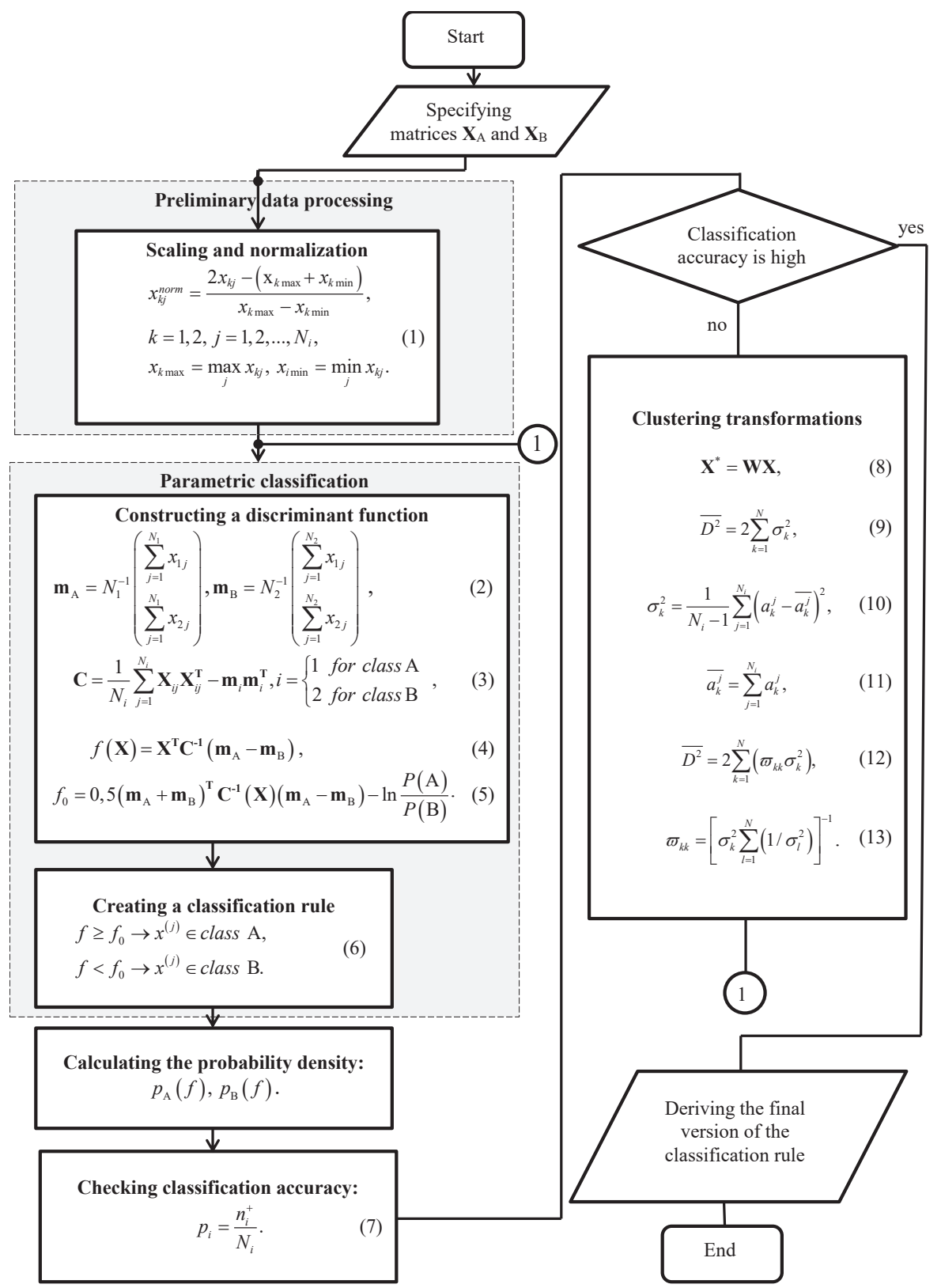

Fig. 3. Algorithm of parametric classification under which the research methodology was implemented 


\section{Results}

Fig. 4 shows the distribution of the $\mathrm{SiO}_{2}$ and $\mathrm{FeO}+\mathrm{Fe}_{2} \mathrm{O}_{3}$ feature factor values for the low-temperature and high-temperature modes in natural form according to Table $\mathbf{1}$ for time intervals $0-40$. The data line for the time point 50 for the low-temperature mode is not included in the original sample in order to subsequently check the predictive ability of the resulting classification rule.

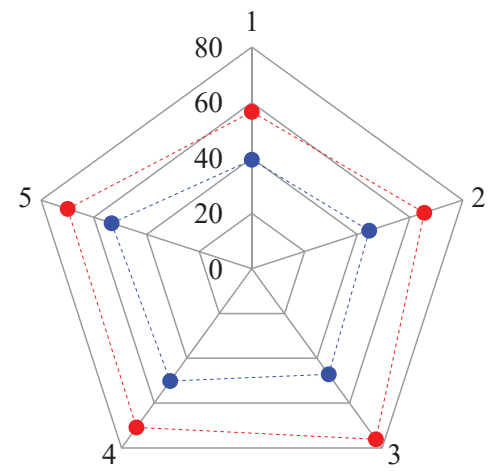

-- $\mathrm{SiO}_{2}, \%$ high-temperature mode

-.- $\mathrm{SiO}_{2}, \%$ low-temperature mode

a

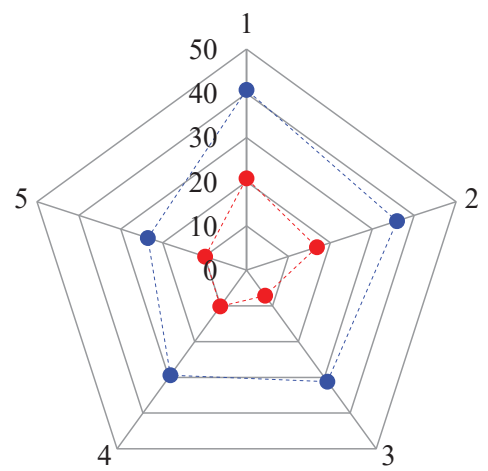

- $-\mathrm{FeO}+\mathrm{Fe}_{2} \mathrm{O}_{3}, \%$ high-temperature mode

- $-\mathrm{FeO}+\mathrm{Fe}_{2} \mathrm{O}_{3}, \%$ low-temperature mode b

Fig. 4. Diagram of feature factor values: $a-\mathrm{SiO}_{2}, \% ; b-\mathrm{FeO}+\mathrm{Fe}_{2} \mathrm{O}_{3}, \%$

Table 2 shows the results of calculating the statistical characteristics - estimates of mathematical expectation $M(x)$ and standard deviation $s$, as well as ranges of the feature factors for each of the modes in natural form.

Table 2

Results of calculating the statistical characteristics of the feature factors for each of the modes

\begin{tabular}{|c|c|c|c|c|}
\hline \multirow{3}{*}{ Sample number } & \multicolumn{2}{|c|}{ High-temperature mode (Class B) } & \multicolumn{2}{|c|}{ Low-temperature mode (Class A) } \\
\hline & \multicolumn{4}{|c|}{ Slag components } \\
\hline & $\mathrm{SiO}_{2}$ & $\mathrm{FeO}+\mathrm{Fe}_{2} \mathrm{O}_{3}$ & $\mathrm{SiO}_{2}$ & $\mathrm{FeO}+\mathrm{Fe}_{2} \mathrm{O}_{3}$ \\
\hline 1 & 56.62 & 20.78 & 39.32 & 40.77 \\
\hline 2 & 65.38 & 16.82 & 44.55 & 35.92 \\
\hline 3 & 76.18 & 7.14 & 47.16 & 31.18 \\
\hline 4 & 70.85 & 10.12 & 50.17 & 29.4 \\
\hline 5 & 69.95 & 9.86 & 53.22 & 23.55 \\
\hline$M(x)$ & 67.796 & 12.944 & 46.884 & 32.164 \\
\hline$s$ & 7.331 & 5.648 & 5.331 & 6.538 \\
\hline$x_{i \max }$ & 76.18 & 20.78 & 53.22 & 40.77 \\
\hline$x_{i \min }$ & 56.62 & 7.14 & 39.32 & 23.55 \\
\hline
\end{tabular}

From Table 2 it follows that the range of the $\mathrm{SiO}_{2}$ feature factor values is limited by the values $x_{1 \text { min }}=39.32 \%, x_{1 \max }=76.18 \%$, and the range of variation $\mathrm{FeO}+\mathrm{Fe}_{2} \mathrm{O}_{3}$ feature factor values is limited to $x_{2 \min }=7.14 \%, x_{2 \max }=40.77 \%$. Based on these ranges, the operation of normalization of the «Preliminary data processing» algorithm block (Fig. 3) was performed according to the formula (1). The results of processing are shown in Table 3, where the normalized values of the feature factors $x_{1}$ and $x_{2}$ are denoted by $x_{1}^{\text {norm }}$ and $x_{2}^{\text {norm }}$ respectively.

Tables 4, 5 show the results of calculating all the parameters of the discriminant function of the «Parametric classification» algorithm block (Fig. 3) for classes A and B, respectively. 
Table 3

Results of preliminary data processing

\begin{tabular}{ccccc}
\hline \multirow{2}{*}{ Sample number } & \multicolumn{2}{c}{ High-temperature mode (Class B) } & Low-temperature mode (Class A) \\
\cline { 2 - 5 } & \multicolumn{4}{c}{ Slag components } \\
\cline { 2 - 5 } & $x_{1}^{\text {norm }}$ & $x_{2}^{\text {norm }}$ & $x_{1}^{\text {norm }}$ & $x_{2}^{\text {norm }}$ \\
\hline 1 & -0.06131 & -0.18882 & -1 & 1 \\
2 & 0.413999 & -0.42432 & 0.169598 & 0.711567 \\
3 & 1 & -1 & 0.23812 & 0.429676 \\
4 & 0.710798 & -0.82278 & 0.317693 & 0.323818 \\
5 & 0.661964 & -0.83824 & 0.393923 & -0.02409 \\
$M(x)$ & 0.54509 & -0.65483 & 0.023867 & 0.488195 \\
$S$ & 0.398 & 0.336 & 0.579 & 0.389
\end{tabular}

Table 4

Results of calculating the parameters of the discriminant function for class A

\begin{tabular}{ccc}
\hline $\mathbf{m}_{\mathrm{A}}$ & $\mathbf{C}=\left(\begin{array}{l}\mathrm{a}_{1} \\
\mathrm{a}_{2}\end{array}\right)=\mathbf{C}^{-1}\left(\mathbf{m}_{\mathrm{A}}-\mathbf{m}_{\mathrm{B}}\right)$ & $\boldsymbol{f}_{\mathbf{0}}$ \\
\hline$\left(\begin{array}{l}0.023867 \\
0.488195\end{array}\right)$ & $\left(\begin{array}{ll}0.126594 & -0.10382 \\
-0.10382 & 0.090258\end{array}\right)$ & $\left(\begin{array}{l}10.27893 \\
22.06121\end{array}\right)$
\end{tabular}

Table 5

Results of calculating the parameters of the discriminant function for class B

\begin{tabular}{|c|c|c|c|}
\hline $\mathbf{m}_{\mathrm{B}}$ & $\mathrm{C}$ & $\mathbf{A}=\left(\begin{array}{l}\mathrm{a}_{1} \\
\mathrm{a}_{2}\end{array}\right)=\mathbf{C}^{-1}\left(\mathbf{m}_{\mathrm{A}}-\mathbf{m}_{\mathrm{B}}\right)$ & $f_{0}$ \\
\hline$\left(\begin{array}{l}0.54509 \\
-0.65483\end{array}\right)$ & $\left(\begin{array}{cc}0.267744 & -0.14838 \\
-0.14838 & 0.120944\end{array}\right)$ & $\left(\begin{array}{l}110.5798 \\
139.8582\end{array}\right)$ & 19.80475 \\
\hline
\end{tabular}

From the general form of formula (4) of the «Constructing a discriminant function» algorithm block (Fig. 3) it follows that $f(\mathbf{X})$ is a linear form $L\left(x_{1}^{\text {norm }}, x_{2}^{\text {norm }}\right)$. Therefore, the condition for assigning objects to one of the classes (6) of the «Creating a classification rule» algorithm block (Fig. 3) can be written as follows:

- if the classification rule is based on the use of the covariance matrix for class A (Table 4):

$$
\begin{aligned}
& L\left(x_{1}^{\text {norm }}, x_{2}^{\text {norm }}\right)-1.086018 \geq 0 \rightarrow x^{(j)} \in \text { class } \mathrm{A}, \\
& L\left(x_{1}^{\text {norm }}, x_{2}^{\text {norm }}\right)-1.086018<0 \rightarrow x^{(j)} \in \text { class } \mathrm{B},
\end{aligned}
$$

where $L\left(x_{1}^{\text {norm }}, x_{2}^{\text {norm }}\right)=\mathbf{X A}=\left(\begin{array}{ll}x_{1}^{\text {norm }} & x_{2}^{\text {norm }}\end{array}\right)\left(\begin{array}{l}10.27893 \\ 22.06121\end{array}\right)=10.27893 x_{1}^{\text {norm }}+22.06121 x_{2}^{\text {norm }}$;

- if the classification rule is based on the use of the covariance matrix for class B (Table 5):

$$
\begin{aligned}
& L\left(x_{1}^{\text {norm }}, x_{2}^{\text {norm }}\right)-19.80475 \geq 0 \rightarrow x^{(j)} \in \text { class } \mathrm{A}, \\
& L\left(x_{1}^{\text {norm }}, x_{2}^{\text {norm }}\right)-19.80475<0 \rightarrow x^{(j)} \in \text { class } \mathrm{B},
\end{aligned}
$$

where $L\left(x_{1}^{\text {norm }}, x_{2}^{\text {norm }}\right)=\mathbf{X A}=\left(\begin{array}{ll}x_{1}^{\text {norm }} & x_{2}^{\text {norm }}\end{array}\right)\left(\begin{array}{l}110.5798 \\ 139.8592\end{array}\right)=110.5798 x_{1}^{\text {norm }}+139.8592 x_{2}^{\text {norm }}$. 
Assuming that the found sample distribution parameters for classes $\mathrm{A}$ and $\mathrm{B}$ correspond to the general ones, it is possible to build probability density graphs $p_{\mathrm{A}}(f), p_{\mathrm{B}}(f)$ for the cases if the classification rule is based on the use of the covariance matrix for class A and for class B (Fig. 5, 6, respectively).

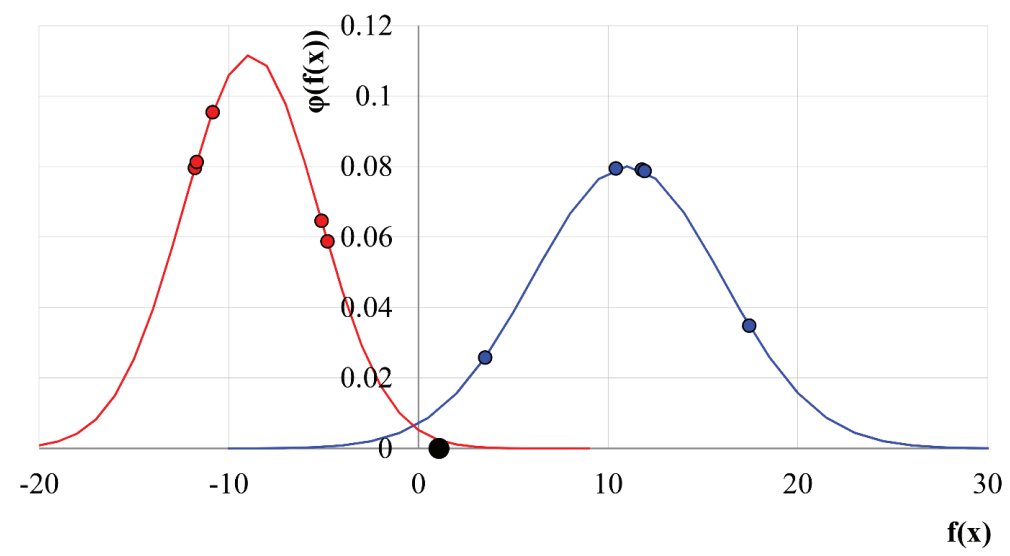

- Low-temperature mode

- High-temperature mode

- f0

Fig. 5. Probability densities $p_{\mathrm{A}}(f), p_{\mathrm{B}}(f)$ for the cases when the classification rule is based on the use of the covariance matrix for class A; markers show the calculated values for the experimental points (Table 3)

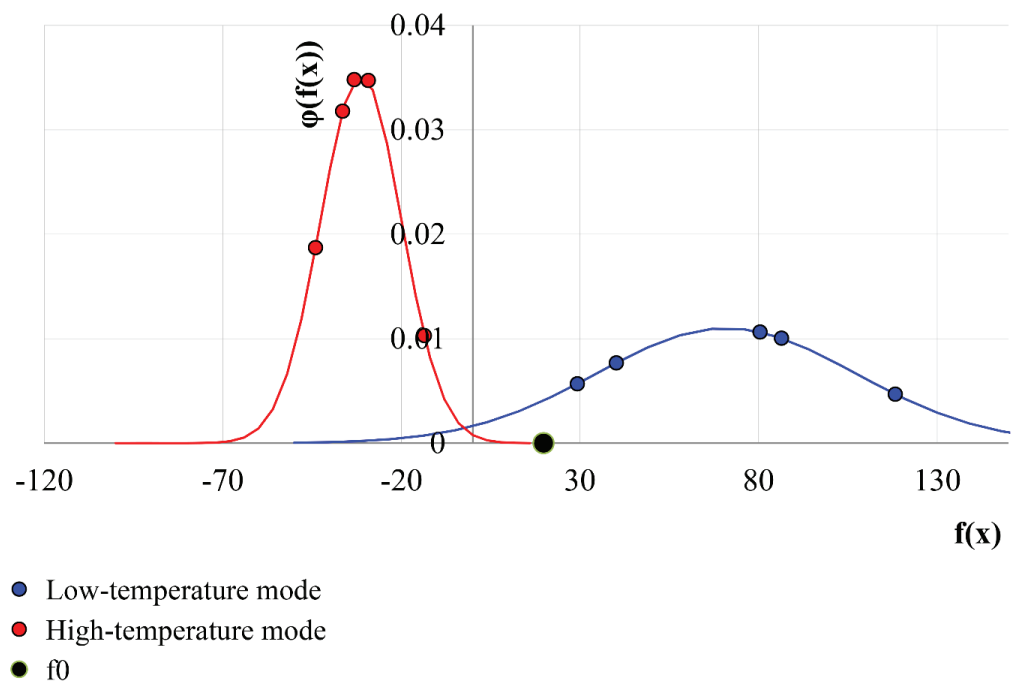

Fig. 6. Probability densities $p_{\mathrm{A}}(f), p_{\mathrm{B}}(f)$ for the cases when the classification rule is based on the use of the covariance matrix for class B; markers show the calculated values for the experimental points (Table 3)

The results obtained indicate that there is a classification error, which is greater if the classification rule is based on the use of the covariance matrix for class B (Fig. 5, 6). Therefore, it is preferable to use the classification rule based on the use of the covariance matrix for class A. In this case, the line separating the classes has the form shown in Fig. 7.

Fig. 7 shows that all objects are classified correctly. Therefore, despite the fact that experimental point No. 1 with coordinates $(-0.06131 ;-0.18882)$ for class A and experimental point No. 1 with coordinates $(-1 ; 1)$ for class B make a negative contribution to minimizing the intra-class distance, operations (8)-(13) of the «Clustering transformations» algorithm block (Fig. 3) were not carried out. 


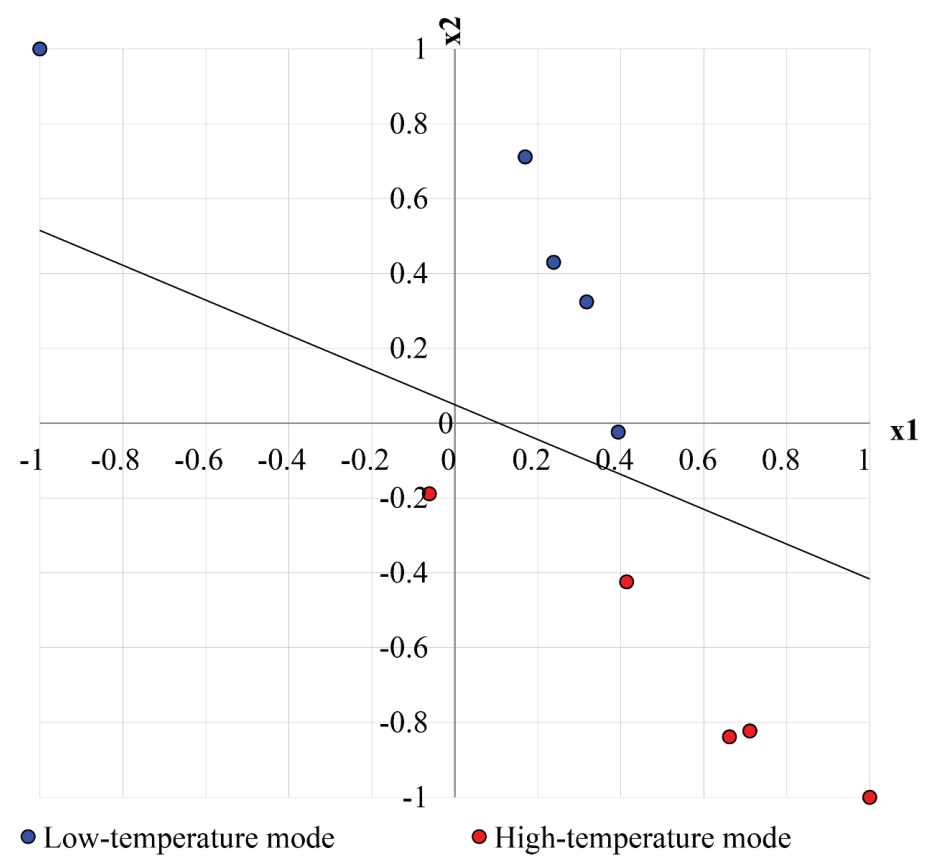

Fig. 7. Separating line $10.27893 x_{1}^{\text {norm }}+22.06121 x_{2}^{\text {norm }}=1.086018$ and location of experimental points in the normalized feature factor space $\left(x_{1}^{\text {norm }}-x_{2}^{\text {norm }}\right)$ by clusters - classes A and B

To form the condition for the absence of parametric failure of the temperature control system of induction crucible melting, the following designations are introduced:

$\operatorname{Tm}(T)$ - process mode, depending on one variable - melt temperature, which means the following: the factor of identification of the process mode is the «temperature» parameter;

$\operatorname{Tm}(T) \downarrow$ - low-temperature melting mode, temperature ranges of $1.200 \leq T \leq 1.300$ (Fig. 1);

$\operatorname{Tm}(T) \uparrow$ - high-temperature melting mode, temperature ranges of $1.400 \leq T \leq 1.500$ (Fig. 1);

$[\operatorname{Tm}(T)]$ - melting temperature mode specified by the process conditions;

$\Delta(\mathrm{Tm})$ - parametric failure function, which is a quantitative characteristic for evaluating the parametric reliability of the temperature control system based on recording events that the temperature mode does not correspond to the specified process. The function can take two values: $« 0 »-$ if there is no parametric failure, «1»- if the parametric failure is recorded.

Taking into account these designations and the classification rule based on the use of the covariance matrix for class $\mathrm{A}$ in the space of normalized feature factors $x_{1}^{\text {norm }}$ and $x_{2}^{\text {norm }}$, the parametric failure function can be represented as follows.

$$
\Delta(\operatorname{Tm})=\left\{\begin{array}{l}
0,[\operatorname{Tm}(T)] \Leftrightarrow \operatorname{Tm} \downarrow \wedge L\left(x_{1}^{\text {norm }}, x_{2}^{\text {norm }}\right)-1.086018 \geq 0, \\
1,[\operatorname{Tm}(T)] \Leftrightarrow \operatorname{Tm} \downarrow \wedge L\left(x_{1}^{\text {norm }}, x_{2}^{\text {norm }}\right)-1.086018<0,
\end{array}\right.
$$

or in the equivalent form:

$$
\Delta(\operatorname{Tm})=\left\{\begin{array}{l}
0,[\operatorname{Tm}(T)] \Leftrightarrow \operatorname{Tm} \uparrow \wedge L\left(x_{1}^{\text {norm }}, x_{2}^{\text {norm }}\right)-1.086018<0, \\
1,[\operatorname{Tm}(T)] \Leftrightarrow \operatorname{Tm} \uparrow \wedge L\left(x_{1}^{\text {norm }}, x_{2}^{\text {norm }}\right)-1.086018 \geq 0 .
\end{array}\right.
$$

The text version of this function, for example (14), is as follows.

If the process conditions specify the low-temperature melting mode $([\operatorname{Tm}(T)] \Leftrightarrow \operatorname{Tm} \downarrow)$, then parametric failure is absent only if the point with coordinates $\left(x_{1}^{\text {norm }} x_{2}^{\text {norm }}\right)$ is located in cluster A.

If the process conditions set the low-temperature melting mode, and the point with coordinates $\left(x_{1}^{\text {norm }} x_{2}^{\text {norm }}\right)$ is located in cluster $\mathrm{B}$, then a parametric failure is recorded. 


\section{Discussion}

The parametric failure function obtained in the form of (14) or (15) allows recording the time points at which $\Delta(T)=1$, which form the flow of events qualified as parametric failures of the temperature control system of induction crucible melting. This allows, during short-term or longterm observations, depending on the rate of parametric failures, evaluating failure flow parameters for planning maintenance or organizational and technical solutions aimed at minimizing violations of the melting regulations. Obviously, the result of such measures is improved control quality of the process as a whole, assessed on the basis of the WECQ-Algorithm [27].

It should be noted that for the practical use of this function, it is necessary to first convert the natural values of $\mathrm{SiO}_{2}$ and $\mathrm{FeO}+\mathrm{Fe}_{2} \mathrm{O}_{3}$ into normalized ones $x_{1}^{\text {norm }}$ and $x_{2}^{\text {norm }}$ according to the formulas:

$$
\begin{gathered}
x_{1}^{\text {norm }}=\frac{\left(\mathrm{SiO}_{2}\right)-57.75}{18.43}, \\
x_{2}^{\text {norm }}=\frac{\left(\mathrm{FeO}+\mathrm{Fe}_{2} \mathrm{O}_{3}\right)-23.955}{16.815},
\end{gathered}
$$

where the numerical values in the numerator correspond to the average content of the slag component over the range (Table 2):

$$
\begin{aligned}
& -\mathrm{SiO}_{2}, \%: 39.32 \leq\left(\mathrm{SiO}_{2}\right) \leq 76.18, \\
& -\mathrm{FeO}+\mathrm{Fe}_{2} \mathrm{O}_{3}, \%: 7.14 \leq\left(\mathrm{FeO}+\mathrm{Fe}_{2} \mathrm{O}_{3}\right) \leq 40.77,
\end{aligned}
$$

and the numerical values in the denominator correspond to the range of the slag component content:

$-\mathrm{SiO}_{2}, \%: \mathrm{I}_{\left(\mathrm{SiO}_{2}\right)}=\left(\mathrm{SiO}_{2}\right)_{\max }-57.75=57.75-\left(\mathrm{SiO}_{2}\right)_{\min },\left(\mathrm{SiO}_{2}\right)_{\max }=76.18 \%,\left(\mathrm{SiO}_{2}\right)_{\min }=39.32 \%$,

$-\mathrm{FeO}+\mathrm{Fe}_{2} \mathrm{O}_{3}, \%: \mathrm{I}_{\left(\mathrm{FeO}+\mathrm{Fe}_{2} \mathrm{O}_{3}\right)}=\left(\mathrm{FeO}+\mathrm{Fe}_{2} \mathrm{O}_{3}\right)_{\max }-23.955=23.955-\left(\mathrm{FeO}+\mathrm{Fe}_{2} \mathrm{O}_{3}\right)_{\min }$, $\left(\mathrm{FeO}+\mathrm{Fe}_{2} \mathrm{O}_{3}\right)_{\max }=40.77 \%,\left(\mathrm{FeO}+\mathrm{Fe}_{2} \mathrm{O}_{3}\right)_{\min }=7.14 \%$.

It is important to note that the parametric failure function (14), (15) is valid only within the specified ranges of the $\mathrm{SiO}_{2}$ and $\mathrm{FeO}+\mathrm{Fe}_{2} \mathrm{O}_{3}$ content. Outside these ranges, it may not work. This is a limitation of this study. However, even within the specified range, there is a zone of uncertainty regarding the assignment of an object to one of the classes, which is determined by the overlap area of the distribution density curves $p_{\mathrm{A}}(f), p_{\mathrm{B}}(f)$, taking into account the classification error. To confirm this, it is possible to check the possibility of correct classification of experimental point No. 6 (Table 1): $\left(\mathrm{SiO}_{2}\right)=54.91 \%$, $\left(\mathrm{FeO}+\mathrm{Fe}_{2} \mathrm{O}_{3}\right)=23.11 \%$, which in the normalized factor space corresponds to the point with coordinates $\left(x_{1}^{\text {norm }} x_{2}^{\text {norm }}\right)=(-0.154-0.05)$. Fig. 8 shows that this point is classified incorrectly, that is, it is erroneously assigned to class B, although it actually belongs to class A (the process was carried out in the low-temperature mode - Table 1). This is also confirmed by the calculation of the value of the discriminant function at the point $\left(x_{1}^{\text {norm }} x_{2}^{\text {norm }}\right)=(-0.154-0.05): f(x)=-2.686$, which violates the condition of assigning an object to class A: $f(x)=-2.686<1.086$ (Fig. 9).

This result is due to the fact that to construct the classification rule, a general data sample for time intervals 0-40 was used, and the tested point was in the zone of uncertainty: for the low-temperature mode, data from the ranges of $39.32 \leq\left(\mathrm{SiO}_{2}\right) \leq 53.22,23.55 \leq\left(\mathrm{FeO}+\mathrm{Fe}_{2} \mathrm{O}_{3}\right) \leq 40.77$ that the test point did not get into were used. The obtained result indicates that in such cases the use of the parametric failure function in the form of (14) will lead to a false conclusion. To avoid this, a restriction on the use of (14) should be imposed, taking into account the permissible ranges of the feature factor values in the normalized form: $-1 \leq x_{1}^{\text {norm }} \leq 0.2458$ and $-0.024 \leq x_{2}^{\text {norm }} \leq 1$.

Another restriction on the practical application of the parametric failure function in the form of (14) or (15) is the need to ensure that other process factors correspond to the specified ones. For example, the charge quality and stability of charging are important, which should ensure such a chemical composition of the melt at the start of heat treatment, that, at a given temperature mode at the moment of the melt delivery from the furnace, for each element would fall into the required range, regulated by the alloy quality requirement.

It should also be noted that the choice of feature factors in this study was based on practical experience rather than strict significance verification of other feature factors, which could not but affect the quality of the constructed decision rule. Carrying out an appropriate procedure would improve the accuracy of classification by increasing the size of the factor space. 


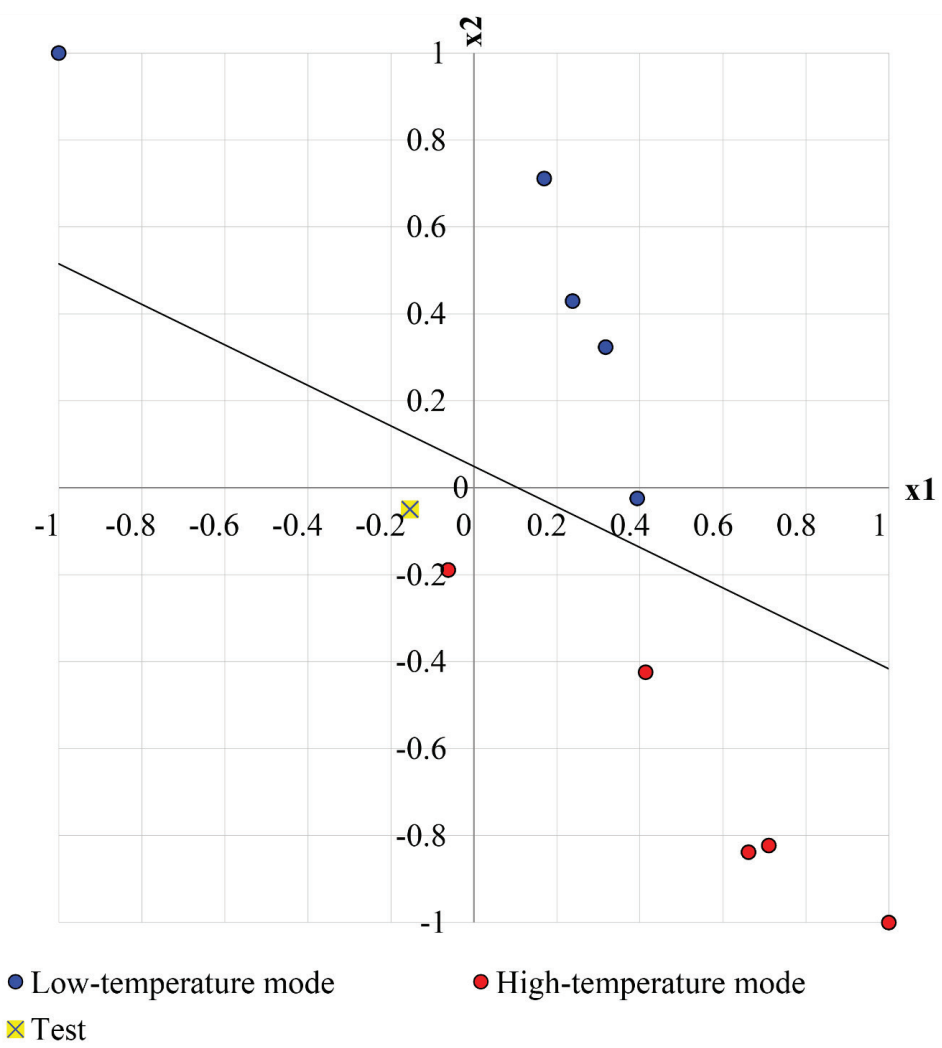

Fig. 8. Results of the test verification of the accuracy of classification of experimental point No. 6 in the normalized feature factor space $\left(x_{1}^{\text {norm }}-x_{2}^{\text {norm }}\right)$ by clusters - classes A and B

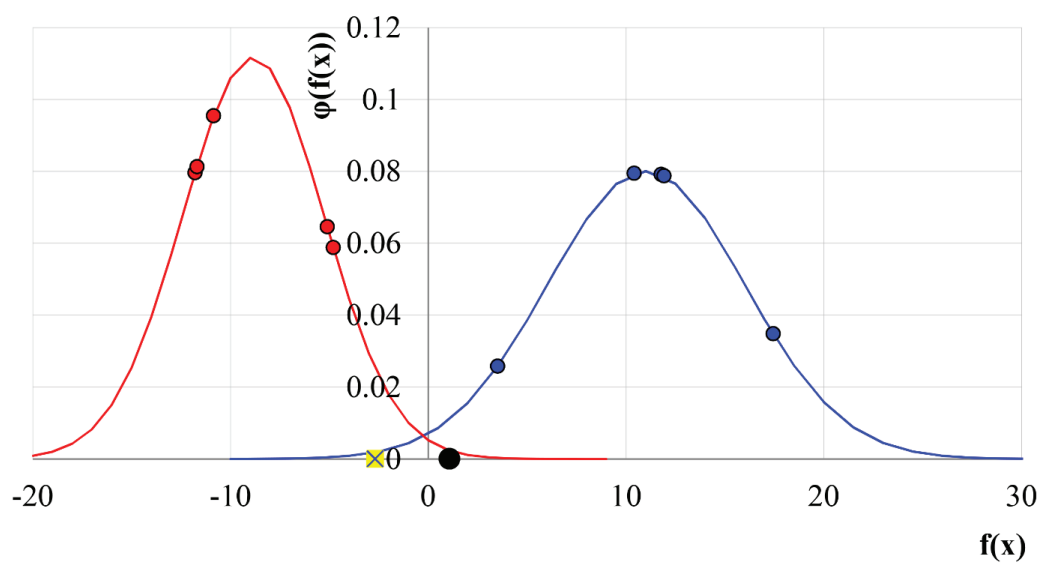

- Low-temperature mode

- High-temperature mode

f0

Fig. 9. Results of the test verification of the accuracy of classification of experimental point No. 6 based on the calculation of the discriminant function

Thus, there is reason to believe that a solution to the problem of incorrect classification may be to minimize the area of the uncertainty zone. For this, it is necessary to construct a classification rule for a larger sample, with the inclusion of additional significant feature factors, choosing the geometry of clusters and distribution of experimental points in them so that the condition of equality of dispersion matrices is satisfied [28]. This can be a direction for further research aimed at improving the accuracy and predictive ability of the parametric failure function. 


\section{Conclusions}

It was found that by the composition of induction crucible melting slag, it is possible to determine the temperature mode at which the process was carried out. To do this, in the space of feature factors, composed of slag components, it is necessary to construct a classification rule, which allows assigning the melting mode to one of two classes: $\mathrm{A}-\ll$ low-temperature mode» $\left(T=1.250 \pm 50{ }^{\circ} \mathrm{C}\right)$, $\mathrm{B}$ - «high-temperature mode» $\left(T=1.450 \pm 50{ }^{\circ} \mathrm{C}\right)$. Based on a small sample of data in the normalized space of feature factors, which are the content of $\mathrm{SiO}_{2}$ and $\mathrm{FeO}+\mathrm{Fe}_{2} \mathrm{O}_{3}$ in slag, a discriminant function is constructed and a decision rule is obtained, which has the form of a linear classifier $L\left(x_{1}^{\text {norm }}, x_{2}^{\text {norm }}\right)-1.086018 \geq 0 \rightarrow x^{(j)} \in$ class A, $L\left(x_{1}^{\text {norm }}, x_{2}^{\text {norm }}\right)-1.086018<0 \rightarrow x^{(j)} \in$ class $\mathrm{B}$.

This rule is the basis for identifying an event qualified as a parametric failure and is included in the general structure of the parametric failure function. This function, built for the temperature control system of induction crucible melting, makes it possible to ascertain that the control system does not meet the specified requirements regulated by a specific temperature mode of melting. The parametric failure function can take two values: «0» - if there is no parametric failure, «1»-if a parametric failure is recorded, and the mechanism of inferencing based on this function is as follows. If the classification rule shows that the object belongs to the class «low-temperature mode», although the process under these conditions should have been carried out in the high-temperature mode, a parametric failure $(\Delta(\mathrm{Tm})=1)$ is recorded. The inferencing mechanism works in a similar way if, on the basis of the classification rule, it is revealed that the process was carried out in the high-temperature mode, although under these conditions it should have been carried out in the low-temperature mode.

On the basis of this, a flow of events qualified as parametric failures can be formed, which allows further simulation of the system operation, making adjustments to the operation process. This will allow, in particular, planning the maintenance of the temperature control system integrated into the melting complex, or organizational and technical measures aimed at minimizing violations of the melting regulations.

It is found that using the range of the values of the feature factors $39.32 \leq\left(\mathrm{SiO}_{2}\right) \leq 76.18$, $7.14 \leq\left(\mathrm{FeO}+\mathrm{Fe}_{2} \mathrm{O}_{3}\right) \leq 40.77$ common for the two classes, the obtained decision rule is operable only when the restrictions imposed by the ranges of the content of slag components for the low-temperature mode $39.32 \leq\left(\mathrm{SiO}_{2}\right) \leq 53.22,23.55 \leq\left(\mathrm{FeO}+\mathrm{Fe}_{2} \mathrm{O}_{3}\right) \leq 40.77$ are met.

\section{References}

[1] ABP Induction. Available at: https://abpinduction.com/

[2] FOMET. Available at: https://www.fomet.com

[3] EGES. Available at: http://www.eges.com.tr/

[4] Zinin, Yu. (2008). Predstavlenie nagruzki pri issledovanii shemotehnicheskih modeley tiristornyh preobrazovateley chastoty dlya induktsionnoy plavki metallov. Silovaya elektronika, 1, 73-80.

[5] Valiullina, Z., Zinin, Yu. (2007). Shemotehnicheskoe modelirovanie silovyh drosseley dlya tiristornyh preobrazovateley povyshennoy chastoty. Silovaya elektronika, 1.

[6] Luzgin, V. I., Petrov, A. Yu., Fatkullin, S. M., Frizen, V. E. Induktsionnye plavil'no-liteynye kompleksy dlya proizvodstva vysokokachestvennogo chuguna. Available at: http://xn--jlaboj7cc.xn--plai/upload/image/poslednya_statiya.pdf

[7] Kuvaldin, A. B., Fedin, M. A. Identifikatsiya induktsionnyh tigel'nyh pechey i mikserov kak obektov upravleniya i razrabotka parametricheskoy sistemy regulirovaniya temperatury rasplava. Available at: http://elcut.ru/publications/sbornik1/5kuvaldin.pdf

[8] Dymko, I. (2018). Choice of the optimal control strategy for the duplex-process of induction melting of constructional iron. EUREKA: Physics and Engineering, 4, 3-13. doi: https://doi.org/10.21303/2461-4262.2018.00669

[9] Demin, D. (2017). Synthesis of optimal control of technological processes based on a multialternative parametric description of the final state. Eastern-European Journal of Enterprise Technologies, 3 (4 (87)), 51-63. doi: https://doi.org/10.15587/ 1729-4061.2017.105294

[10] Demin, D. A., Pelikh, V. F., Ponomarenko, O. I. (1995). Optimization of the method of adjustment of chemical composition of flake graphite iron. Liteynoe Proizvodstvo,7-8, 42-43.

[11] Demin, D. A., Pelikh, V. F., Ponomarenko, O. I. (1998). Complex alloying of grey cast iron. Liteynoe Proizvodstvo, 10, $18-19$.

[12] Domin, D. (2013). Artificial orthogonalization in searching of optimal control of technological processes under uncertainty conditions. Eastern-European Journal of Enterprise Technologies, 5 (9 (65)), 45-53. Available at: http://journals.uran.ua/eejet/ article/view/18452/16199 
[13] Demin, D. A. (1998). Change in cast iron's chemical composition in inoculation with a Si-V-Mn master alloy. Litejnoe Proizvodstvo, 6,35 .

[14] Shumihin, V. S., Kutuzov, V. P., Hramchenkov, A. I. et. al.; Aleksandrova, N. N. (Ed.) (1982). Vysokokachestvennye chuguny dlya otlivok. Moscow: Mashinostroenie, 222.

[15] Fraze-Frazenko, O. O. (2012). Method for the regularization of ill-posed problems of recognition in CCTV. Technology Audit and Production Reserves, 6 (4 (8)), 19-20. doi: https://doi.org/10.15587/2312-8372.2012.5638

[16] Vasenko, Yu. A. (2012). Technology for improved wear iron. Technology Audit and Production Reserves, 1 (1 (3)), $17-21$. doi: https://doi.org/10.15587/2312-8372.2012.4870

[17] Ponomarenko, O. I., Trenev, N. S. (2013). Computer modeling of crystallization processes as a reserve of improving the quality of pistons of ICE. Technology Audit and Production Reserves, 6 (2 (14)), 36-40. doi: https://doi.org/10.15587/ 2312-8372.2013.19529

[18] Ignaszak, Z., Popielarski, P., Krawiec, K. (2007). Contribute to quantitative identification of casting defects based on computer analysis of X-ray images. Archives of foundry engineering, 7 (4), 89-94.

[19] Aouati, M. (2017). Parametric identification in the problem of determining the quality of dusulfusation and deposphoration processes of Fe-C alloy. Technology Audit and Production Reserves, 2 (1 (34)), 9-15. doi: https://doi.org/10.15587/ 2312-8372.2017.99130

[20] Aouati, M. (2017). Selection of state variables and algorithms of parametric identification of the object by its kinematic characteristics. ScienceRise, 4 (2), 37-41. doi: https://doi.org/10.15587/2313-8416.2017.99049

[21] Pavlenko, V. D., Fomin, A. A. (2001). Povyishenie tochnosti postroeniya reshayuschego pravila v metodah statisticheskoy klassifikatsii. Elektronnoe modelirovanie, 23 (4), 61-68.

[22] Aouati, M. (2016). Localization of vectors-patterns in the problems of parametric classification with the purpose of increasing its accuracy. Eastern-European Journal of Enterprise Technologies, 4 (4 (82)), 10-20. doi: https://doi.org/10.15587/ $1729-4061.2016 .76171$

[23] Aouati, M. (2017). Improvement of accuracy of parametric classification in the space of $n \times 2$ factors-attributes on the basis of preliminary obtained linear discriminant function. EUREKA: Physics and Engineering, 3, 55-68. doi: https://doi.org/ 10.21303/2461-4262.2017.00362

[24] Shemy induktsionnyh pechey. Available at: http://electricalschool.info/main/electrotehnolog/1136-skhemy-indukcionnykhpechejj.html

[25] Hartman, K., Leckiy, E., Shefer, V. et. al. (1977). Planirovanie ehksperimenta v issledovanii tekhnologicheskih processov. Moscow: Mir, 552.

[26] Stuper, A. J., Brugger, W. E., Jurs, P. C. (1979). Computer Assisted Studies of Chemical Structure and Biological Function. John Wiley \& Sons, 220.

[27] Demin, D. (2019). Development of «whole» evaluation algorithm of the control quality of «cupola - mixer» melting duplex process. Technology Audit and Production Reserves, 3 (1 (47)), 4-24. doi: https://doi.org/10.15587/2312-8372.2019.174449

[28] Aouati, M. (2018). Improving the accuracy of classifying rules for controlling the processes of deculfuration and dephosphorization of Fe-C melt. Technology Audit and Production Reserves, 2 (3 (46)), 10-18. doi: https://doi.org/10.15587/ 2312-8372.2019.169696 